\title{
HIF-1 $\alpha$ inhibition sensitizes pituitary adenoma cells to temozolomide by regulating MGMT expression
}

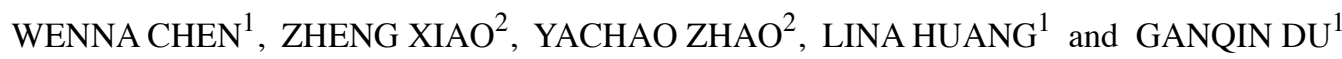 \\ Departments of ${ }^{1}$ Neurology, and ${ }^{2}$ Neurosurgery, The First Affiliated Hospital of \\ Henan University of Science and Technology, Luoyang, Henan 471003, P.R. China
}

Received June 9, 2013; Accepted August 2, 2013

DOI: $10.3892 /$ or.2013.2689

\begin{abstract}
Suppression of hypoxia-inducible factor $1 \alpha$ (HIF-1 $\alpha$ ) has been shown to sensitize glioblastoma cells to temozolomide (TMZ) treatment via down-modulation of $\mathrm{O}^{6}$-methylguanine-DNA methyltransferase (MGMT) expression. To date, whether the efficacy of TMZ therapy is correlated with MGMT expression and whether HIF-1 $\alpha$ suppression exerts similar effects in human pituitary adenoma cells have not been defined. In the present study, using an HIF- $1 \alpha$ knockdown strategy and the HIF-1 $\alpha$ inhibitor 2-methoxyestradiol (2ME), we demonstrated for the first time that HIF-1 $\alpha$ suppression increases the efficacy of TMZ in human pituitary adenoma cells in vitro and in vivo. Our mechanistic study showed that HIF-1 $\alpha$ suppression resulted in down-modulation of MGMT expression and decreased DNA damage repair ability as demonstrated by decreased RAD51 protein expression. These results suggest an HIF-1 $\alpha$-dependent regulation of MGMT expression in human pituitary adenoma cells, and HIF-1 $\alpha$ knockdown or the HIF-1 $\alpha$ inhibitor $2 \mathrm{ME}$ can confer TMZ sensitization in human pituitary adenomas. The clinical application of $2 \mathrm{ME}$ as an adjuvant therapy may be a potential approach to improve the efficacy of TMZ therapy for pituitary adenomas.
\end{abstract}

\section{Introduction}

Pituitary adenomas comprise $10-15 \%$ of all intracranial neoplasms (1). Despite being benign tumors in most cases, nearly $35 \%$ of pituitary adenomas display aggressive biological activity as demonstrated by clinically evident local invasion (2). Although surgery, radiotherapy and pharmaceutical therapy are routinely employed, tumor recurrence of these aggressive adenomas still remains very high, resulting in high morbidity and mortality (3).

Correspondence to: Dr Ganqin Du, Department of Neurology, The First Affiliated Hospital of Henan University of Science and Technology, 24 Jinghua Road, Luoyang, Henan 471003, P.R. China E-mail: ganqindu@163.com

Key words: pituitary adenoma, MGMT, temozolomide, HIF-1 $\alpha$
Temozolomide (TMZ) has been shown to display a promising antitumor effect in certain cases used as the last-line treatment in aggressive pituitary adenomas (4-6). TMZ is an alkylating chemotherapeutic drug capable of crossing the blood-brain barrier, and has been widely used to treat refractory glioblastoma multiforme and neuroendocrine tumors $(7,8)$. However, several clinical trials have shown that the efficacy of TMZ may be dependent on $\mathrm{O}^{6}$-methylguanine-DNA methyltransferase (MGMT) expression and is prone to be poor in tumors with high MGMT expression (9). Since TMZ is only used as the last line therapy for aggressive pituitary adenomas resistant to conventional therapies, it is necessary to develop novel therapeutic approaches to improve the TMZ efficiency in pituitary adenomas.

MGMT is a DNA repair kinase and can remove the methyl/alkyl group from the $\mathrm{O}^{6}$-position of guanine, thereby preventing TMZ-induced DNA damage (9). Modulation of MGMT expression has been proposed as a mean to sensitize tumors to TMZ. Recent studies have shown that suppression of hypoxia-inducible factor $1 \alpha(\mathrm{HIF}-1 \alpha)$ can down-modulate MGMT expression, which in turn overrides glioblastoma multiforme resistance to TMZ (10). We previously described that HIF-1 $\alpha$ is expressed in all types of pituitary adenomas, and HIF-1 $\alpha$ knockdown inhibits hemorrhagic transformation in pituitary adenomas (11). Based on these findings, we hypothesized that HIF-1 $\alpha$ knockdown may also down-modulate MGMT expression in pituitary adenomas, which in turn enhances the efficacy of TMZ in pituitary adenomas.

In order to verify this hypothesis, we enrolled two patients with huge aggressive pituitary adenomas resistant to both conventional and TMZ therapies. The adenoma tissue of the two patients, being identified as high MGMT-expressing tissue after the first operation, was obtained during the second surgery. The tissue from one patient was primary cultured; the tissue from the other patient was equally dissociated and implanted into nude mice. Then, we employed HIF-1 $\alpha$ knockdown strategy to determine the potential regulating effect of HIF-1 $\alpha$ on the MGMT expression in vitro. Furthermore, the correlation between the HIF-1 $\alpha$-MGMT axis and TMZ resistance in pituitary adenomas was also examined in vitro and in vivo. Our results revealed that HIF-1 $\alpha$ regulates MGMT expression, and HIF-1 $\alpha$ knockdown or inhibitor 2-methoxyestradiol (2ME) can enhance the efficacy of TMZ in pituitary adenoma cells via the down-modulation of MGMT expression. 


\section{Materials and methods}

Patients and samples. The present study was approved by the Research Ethics Committee of the Henan University of Science and Technology, Luoyang, China. Prior informed consent was obtained from the patients. Between January 2010 and January 2013, we enrolled two patients harboring huge aggressive pituitary adenomas who had previously undergone one transsphenoidal surgical procedure, one radiation therapy and systemic chemotherapy. After tumor regrowth was confirmed and informed consent from the patients was obtained, treatment with TMZ was offered at the standard therapeutic dose $150 \mathrm{mg} / \mathrm{m}^{2}$ for 5 of every 28 days $(5 / 28)$ as one cycle for 3 cycles (12). After 3 cycles, no response was observed based on MRI. Then, the transsphenoidal surgical procedure was eventually performed in the two patients. The samples were also obtained. For each sample, a small section was fixed with $10 \%$ formalin and embedded in paraffin for histology and immunohistochemical staining, the other was prepared for primary cell culture or tumor implantation in nude mice.

Histology, immunohistochemical staining, cell viability assay, western blot analysis and RT-PCR. All the procedures and reagents employed in the present study are described in our previous reports $(11,13,14)$. Cell viability assay was carried out using Cell Counting Kit-8 (Boster Biological Technology). The following primers for RT-PCR were used: human HIF-1 $\alpha$ F, GCAAGACTTTCCTCAGTCGACACA and R, GCATCC TGTACTGTCCTGTGGTGA; human MGMT F, ATGGAT GTTTGAGCGACACA and R, ATAGAGCAAGGGCAG CGTTA; human GAPDH F, ACGGATTTGGTCGTATTGGG and R, TGATTTTGGAGGGATGTCGC. The primary antibodies used include anti-HIF-1 $\alpha$ (1:1,000; Cell Signaling Technology), anti-MGMT (1:1,000; Santa Cruz Biotechnology), anti-PCNA (1:2,000; Santa Cruz Biotechnology), anti-Rad51 (1:1,000; Santa Cruz Biotechnology) and anti-GAPDH (1:3,000; Santa Cruz Biotechnology).

Primary cultures of pituitary adenoma tissue. After the tissue was obtained, we placed it in complete DMEM and dissociated it using mechanic and enzymatic methods according to the standard protocols immediately. Then, cells were dispersed and filtered through a magnetic bead column coated with anti-fibroblast antibodies. Then, the cells were plated in $16-\left(10^{6}\right.$ cells/well $)$ or 96 -well plates $\left(10^{4}\right.$ cells/well $)$ in the complete DMEM. Twenty-four hours later, a portion of the cells was transiently transfected with $2 \mu \mathrm{g}$ predesigned siRNAs targeting human HIF-1 $\alpha$ or control siRNA duplex via Lipofectamine 2000 (Invitrogen) according to the manufacturer's instructions. The HIF- $1 \alpha$ siRNA sequences were as follows: F, CUGAUGACCAGCAACUUGA and R, UCAAGUUGCUGGUCAUCAG; the mock siRNA sequences were: F, CGUACGCGGAAUACUUCGA and R, UCGAAGUAUUCCGCGUACG; the knockdown efficiency was confirmed by RT-PCR and western blot analysis. The cells were then cocultured with TMZ $(100 \mu \mathrm{M})$ and/or an HIF-1 $\alpha$ inhibitor 2-methoxyestradiol (2ME, $2 \mu \mathrm{M}$ ) for $72 \mathrm{~h}$, then the cell viability assay, RT-PCR and western blot analysis were carried out.
Pituitary adenoma xenografts. In order to increase the tumor formation rate, the tissue were dissociated equally using mechanic methods and were implanted subcutaneously into the lower rear flank of 36 -week-old athymic nude mice. Two weeks later, tumors were formed. Then, tumors were dissociated again, and were equally implanted subcutaneously into the lower rear flank of 12 6-week-old athymic nude mice. After two weeks, the mice were injected with saline, TMZ $(3 \mathrm{mg} / \mathrm{kg}), 2 \mathrm{ME}(25 \mathrm{mg} / \mathrm{kg}), \mathrm{TMZ}(3 \mathrm{mg} / \mathrm{kg})$ plus $2 \mathrm{ME}$ $(25 \mathrm{mg} / \mathrm{kg}$ ) for 5 days (each group, $\mathrm{n}=3$ ). After another three weeks, tumors were harvested. Half of each tumor was frozen in liquid nitrogen for protein analysis and the other half was fixed in $10 \%$ formalin for histology analysis.

Statistical analysis. Statistical software SPSS 13.0 was used for statistical analyses in the present study. Data are expressed as means $\pm \mathrm{SD}$. The Student's t-test and variance analysis were used in the present study. Probability values of $<0.05$ were considered to indicate a statistically significant result.

\section{Results}

Clinical features of the patients. In the present study, two patients with aggressive prolactin (PRL)-secreting adenomas were enrolled. Male patient no. 1 had undergone transsphenoidal surgery against prolactin (PRL)-secreting adenomas in our hospital at the age of 43 in June 2008 following inefficient bromocriptine treatment. In October 2010, the recurrent pituitary adenoma was confirmed by MRI, and external irradiation was carried out and showed poor efficiency. Because the patient refused reoperation after the radiation therapy, TMZ treatment was offered for three months, and no response was observed. The patient then received another transsphenoidal surgery in July 2012, and the tissue was obtained. For male patient no. 2, the transsphenoidal surgery was performed in August 2009 after the lack of efficacy of a half year bromocriptine treatment for prolactin (PRL)-secreting adenomas. Then, MRI showed the recurrent pituitary adenoma in January 2011 and the radiation was initiated without success. The patient denied the operation and received TMZ treatment for three months with no response. The transsphenoidal surgery was then performed in September 2012 and the tissue was obtained.

Characterization of HIF-1 $\alpha$ and MGMT in pituitary adenoma tissue. Although other studies reached an opposite conclusion, MGMT expression has been shown to be responsible for tumor resistance to TMZ in many reports (15-17). Moreover, recent studies have shown that HIF-1 $\alpha$ can modulate MGMT expression and alter the tumor resistance to TMZ in gliomas (10). Therefore, we investigated the HIF-1 $\alpha$ and MGMT expression in pituitary adenoma tissue via RT-PCR, western blot analysis and immunohistochemistry. As expected, we found high expression levels of HIF-1 $\alpha$ and MGMT in the pituitary adenoma tissues from the two patients (Fig. 1).

HIF-1 $\alpha$ knockdown and $2 M E$ downregulate MGMT expression in vitro. HIF-1 $\alpha$ has recently been shown to regulate MGMT expression in gliomas $(10,18)$, yet whether it exerts similar effects in pituitary adenomas has not been examined. In our previous study, we used HIF-1 $\alpha$ knockdown strategy to inhibit 
A

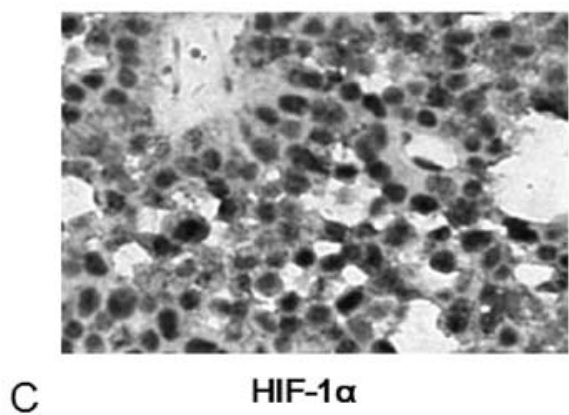

Control NO.1 NO.2

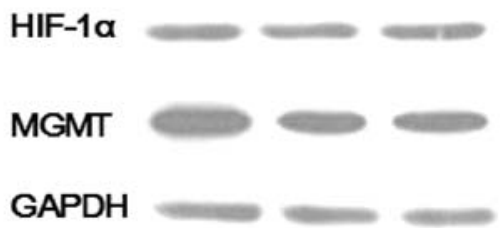

B

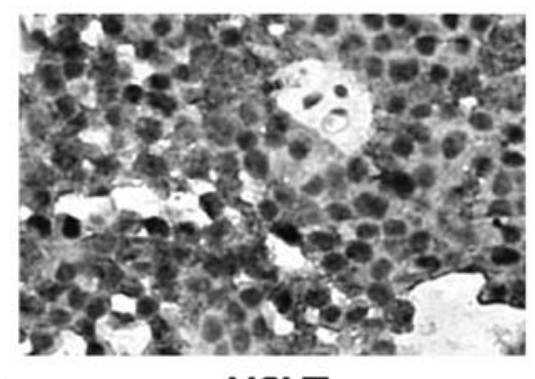

MGMT

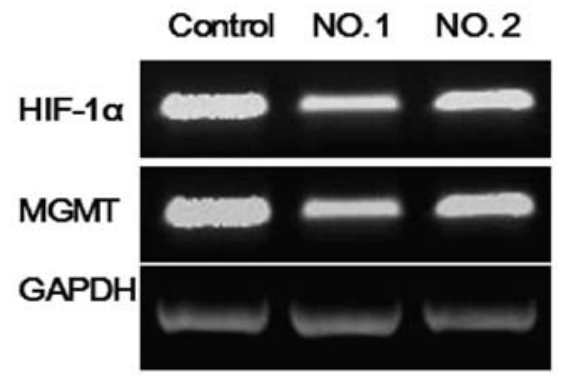

Figure 1. Immunoreactivity for (A) HIF-1 $\alpha$ and (B) MGMT in human pituitary adenoma tissue. (A) HIF-1 $\alpha$, positive cell nuclear and cytoplasmic immunoreactivity of adenomatous cells (original magnification, $\mathrm{x} 400$ ). (B) MGMT, positive cytoplasmic immunoreactivity of adenomatous cells (original magnification, $\mathrm{x} 400$ ). (C) Western blot analysis and (D) RT-PCR confirmed the expression of HIF-1 $\alpha$ and MGMT in human pituitary adenoma tissue. Glioma tissue (HIF-1 $\alpha$ and MGMT-positive) served as the positive control.

A

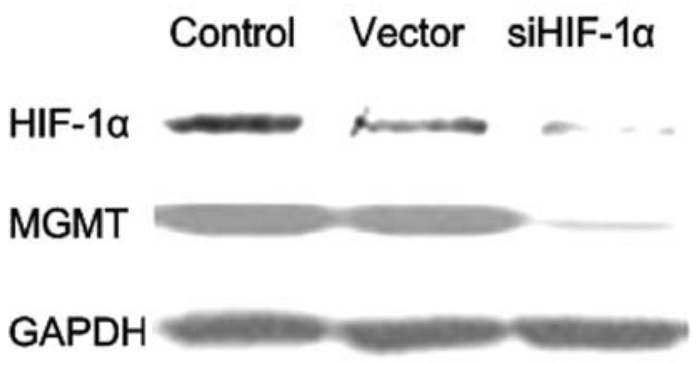

B

Control Vector siHIF-1a 2ME

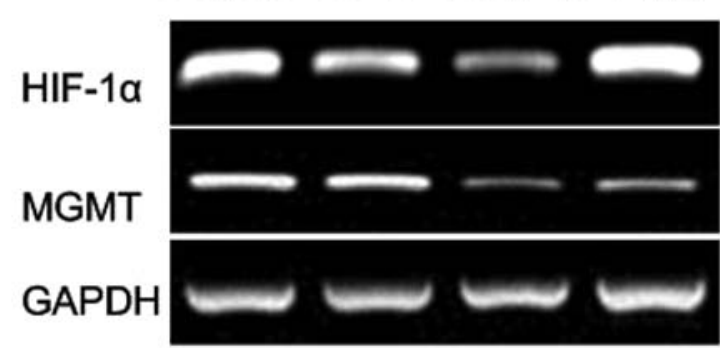

Figure 2. Identification of HIF-1 $\alpha$ knockdown in human pituitary adenoma cells. (A) Western blot analysis and (B) RT-PCR showed that HIF-1 $\alpha$ knockdown decreased the expression levels of HIF-1 $\alpha$ and MGMT in human pituitary adenoma cells. Regarding mRNA expression levels, HIF-1 $\alpha$ inhibitor 2 ME decreased the MGMT expression in human pituitary adenoma cells, while having no effect on HIF-1 $\alpha$ expression.

hemorrhagic transformation in pituitary adenomas (11). In the present study, the HIF-1 $\alpha$ knockdown system was employed for transient transfection in human pituitary adenoma cells from primary culture, and the effect of HIF-1 $\alpha$ knockdown on the MGMT expression was examined. The pituitary adenoma tissue from one patient was primarily cultured immediately after dissection. After a 24-h primary culture, the cells were plated in 16-well plates and were transiently transfected with siHIF-1 $\alpha$ or control siRNA. We found that HIF-1 $\alpha$ knockdown downregulated the MGMT expression in human pituitary adenoma cells in primary culture (Fig. 2A). In order to further clarify this issue, we cocultured human pituitary adenoma cells with $2 \mathrm{ME}(2 \mu \mathrm{M})$ or saline for $72 \mathrm{~h}$, and then the MGMT expression was examined via RT-PCR. As expected, $2 \mathrm{ME}$ downregulated the MGMT expression in vitro (Fig. 2B).
MGMT expression is correlated with TMZ resistance in pituitary adenoma cells. To date, there are still several arguments over whether TMZ efficacy is dependent on MGMT expression in pituitary adenomas. Several clinical trials suggest a correlation between MGMT expression and TMZ efficacy, while other researchers report an opposite trend $(5,19,20)$. Experimental evidence clarifying this issue is lacking. In our pre-experiment, we found that TMZ has no effect on the HIF-1 $\alpha$ and MGMT expression in human pituitary adenomas. In the present study, we investigated the effect of HIF- $1 \alpha$ knockdown and HIF- $1 \alpha$ inhibitor $2 \mathrm{ME}$ on TMZ resistance. HIF- $1 \alpha$ knockdown cells, vector cells and control human pituitary adenoma cells were seeded into 96-well flat-bottomed plates at a concentration of $1 \times 10^{4}$ cells/well. The cells were then cocultured with TMZ (100 $\mu \mathrm{M})$ for $72 \mathrm{~h}$. Another group of human 
A

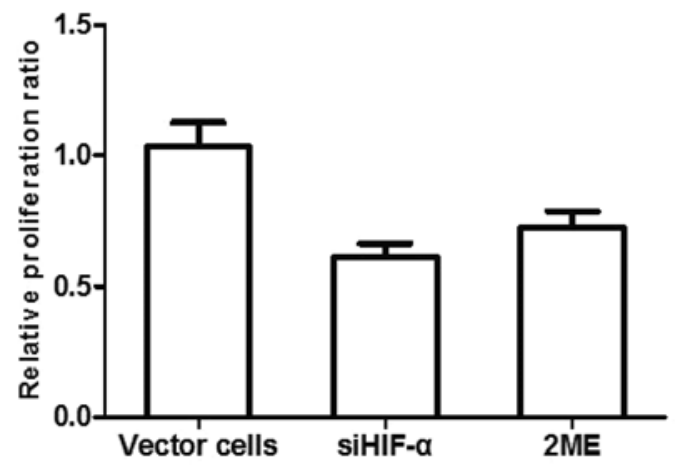

B

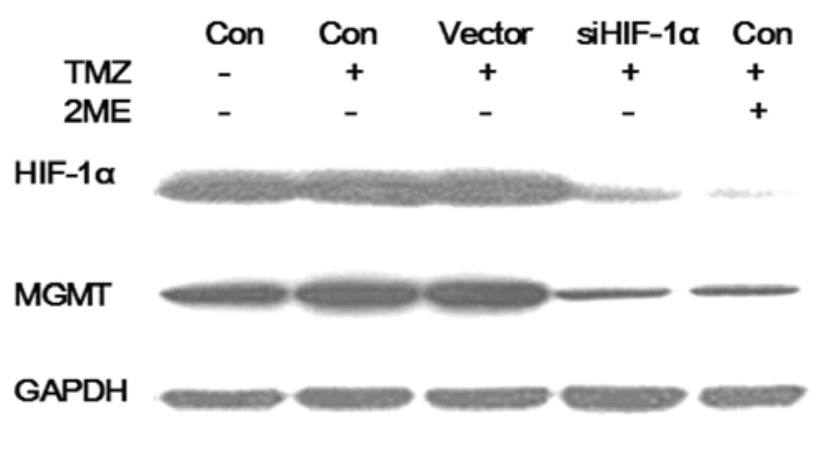

Figure 3. (A) The CCK-8 assay showed that HIF-1 $\alpha$ knockdown and 2ME enhanced the killing effect of TMZ in human pituitary adenoma cells in vitro, while no similar effect of vector siRNA was observed. (B) Effect of TMZ and/or 2ME on the HIF-1 $\alpha$ and MGMT protein expression levels in human pituitary adenoma cells, transfected siHIF-1 $\alpha$ cells and vector siRNA cells. TMZ plus HIF-1 $\alpha$ knockdown or TMZ plus 2 ME decreased the HIF-1 $\alpha$ and MGMT protein expression levels in human pituitary adenoma cells, TMZ alone displayed no effect on control and vector siRNA cells.

A

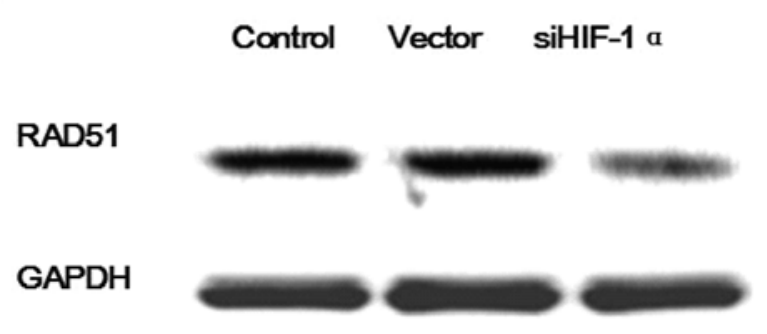

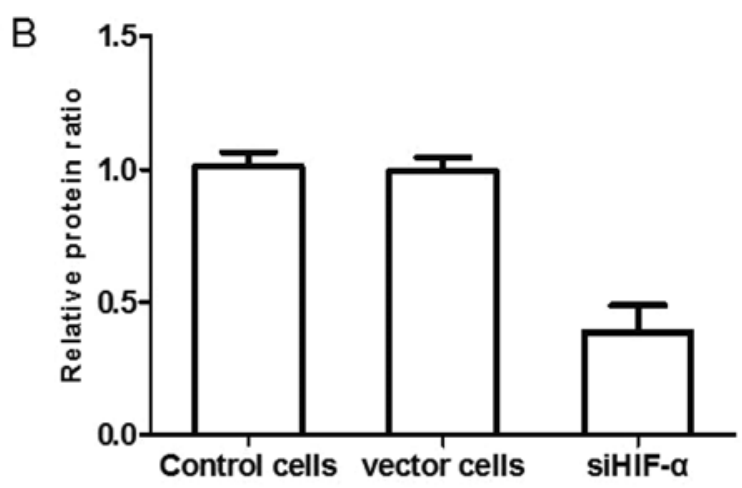

Figure 4. Effect of HIF-1 knockdown on the RAD51 expression levels in human pituitary adenoma cells. (A) Western blot analysis revealed that HIF-1 $\alpha$ knockdown decreased the RAD51 protein expression levels in human pituitary adenoma cells, while no similar effect for the vector siRNA was observed. (B) Densitometric analysis normalized to GAPDH as the loading control is also presented.

pituitary adenoma cells was also seeded and cocultured with TMZ $(100 \mu \mathrm{M})$ plus $2 \mathrm{ME}(2 \mu \mathrm{M})$ for $72 \mathrm{~h}$. Then, the CCK-8 assays were carried out. We found that the relative proliferation ratio of vector cells, siHIF-1 $\alpha$ cells and $2 \mathrm{ME}$ treated cells vs. control cells was $1.01 \pm 0.06,0.62 \pm 0.03$ and $0.72 \pm 0.05 \%$, respectively $(\mathrm{P}<0.05)$. TMZ had no obvious killing effect on human pituitary adenoma cells and vector cells. Compared with the cells treated with TMZ alone, HIF-1 $\alpha$ knockdown and $2 \mathrm{ME}$ significantly reduced the proliferation of cells when combined with TMZ treatment (Fig. 3A). In order to further clarify this issue, the HIF- $1 \alpha$ and MGMT expression in each group was also investigated. As shown in Fig. 3B, TMZ or vector siRNA displayed no effect on the HIF-1 $\alpha$ and MGMT expression, while TMZ plus HIF-1 $\alpha$ knockdown or TMZ plus 2ME significantly reduced the HIF-1 $\alpha$ and MGMT expression in human pituitary adenoma cells. These results indicate that TMZ efficacy may be dependent on the MGMT expression in pituitary adenomas.

HIF-1a knockdown sensitizes pituitary adenoma cells to $T M Z$ via suppressing the repair ability of DNA damage in vitro. Since MGMT expression has been associated with the DNA damage repair ability (21), we inferred that downmodulation of MGMT may also enhance TMZ efficacy via suppression of DNA damage repair ability. As RAD51 is a protein marker associated with DNA damage repair ability (22), the pituitary adenoma cells (control), vector cells and HIF-1 $\alpha$ knockdown cells were cultured with TMZ for $72 \mathrm{~h}$, then RAD51 protein expression was examined. As shown in Fig. 4 , the relative protein ratio of vector cells, siHIF-1 $\alpha$ cells vs. control cells was $0.99 \pm 0.03$ and $0.38 \pm 0.05 \%$, respectively $(\mathrm{P}<0.05)$, which showed that HIF-1 $\alpha$ knockdown of pituitary adenoma cells significantly decreased the RAD51 protein expression compared with the control group. These results indicate that MGMT may be involved in sensitizing pituitary adenoma cells to TMZ via suppression of the repair ability of DNA damage.

$2 M E$ sensitizes pituitary adenoma cells to TMZ in vivo. To translate our above in vitro findings into an in vivo model of pituitary adenoma, we evaluated the effect of HIF-1 $\alpha$ inhibitor 2ME on the MGMT expression and the tumor xenograft proliferation of human pituitary adenoma cells in athymic nude mice. Mice were randomized into four groups: control (saline) group, 2ME group, TMZ group and 2ME plus TMZ group, with three mice in each group. Mice were treated with $2 \mathrm{ME}$ (25 mg/kg), TMZ ( $3 \mathrm{mg} / \mathrm{kg}$ ) or $2 \mathrm{ME}$ plus TMZ for 5 days. Three weeks later, tumors were harvested for analysis. We 

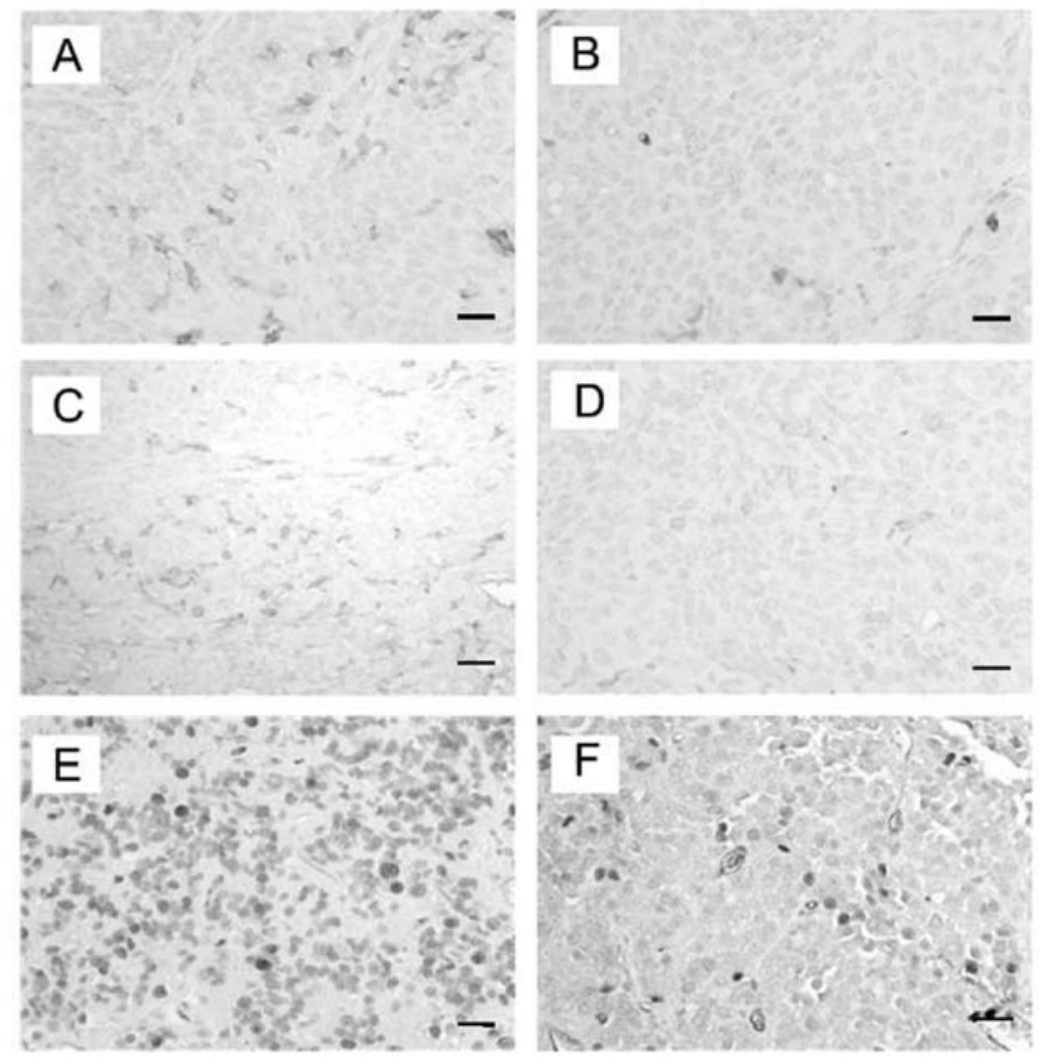

Figure 5. 2ME plus TMZ treatment decreases the expression levels of HIF-1 $\alpha$, MGMT and PCNA in vivo, compared with TMZ treatment alone. Representive image of (A and B) HIF-1 $\alpha,(\mathrm{C}$ and D) MGMT and (E and F) PCNA staining in human pituitary adenoma cell xenografts treated with (A, C and E) TMZ or (B, D and F) TMZ plus the HIF-1 $\alpha$ inhibitor 2ME. Scale bar, $10 \mu \mathrm{m}$.
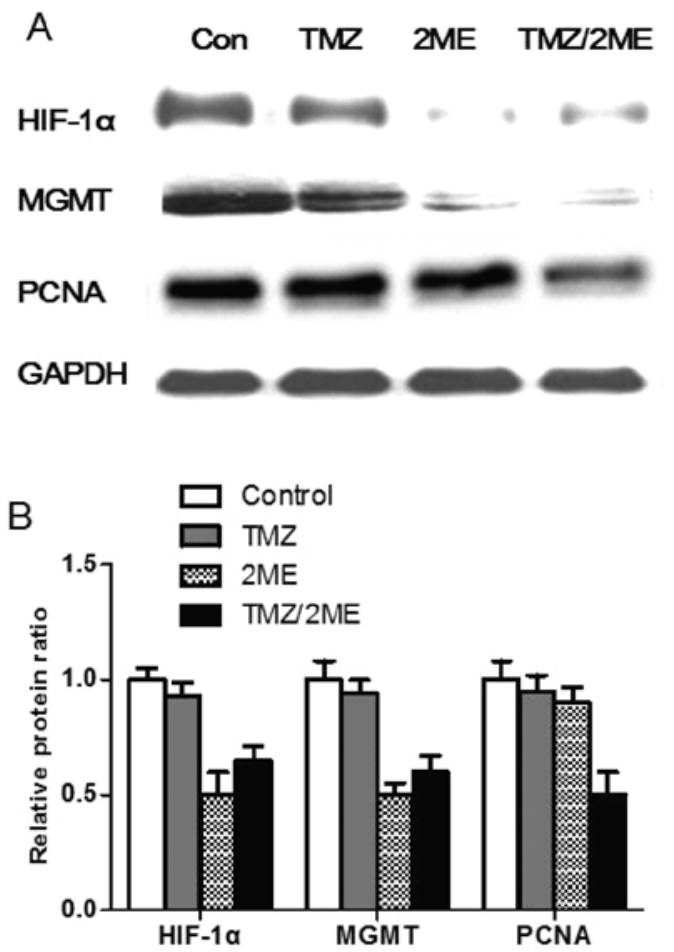

Figure 6. 2ME plus TMZ treatment decreases the expression levels of HIF-1 $\alpha$, MGMT and PCNA in vivo, compared with TMZ or 2ME treatment alone. (A) Western blot analysis revealed that $2 \mathrm{ME}$ or $2 \mathrm{ME}$ plus TMZ treatment decreased the HIF-1 $\alpha$ and MGMT protein expression levels in human pituitary adenoma cells. TMZ exerted no obvious effect on the MGMT protein expression in vivo. (B) Densitometric analysis normalized to GAPDH as the loading control is also presented. found that $2 \mathrm{ME}$ treatment downregulated HIF-1 $\alpha$ and MGMT expression in the tumor xenografts, while no similar effect was observed following TMZ treatment alone (Figs. 5 and 6). Since the human pituitary adenoma cells from the primary culture grew very slowly in nude mice, we did not measure a significant difference in tumor diameter among the different groups. Since PCNA is a marker of tumor proliferation, we examined the PCNA expression in tumors of the different groups. As shown in Figs. 5 and 6, we found no significant difference in the PCNA expression levels among the 2ME group, the TMZ group and the control group. The xenografts of $2 \mathrm{ME}$ plus TMZ group displayed significantly lower PCNA expression than the other groups. The relative PCNA protein ratio of the vector cells, siHIF-1 $\alpha$ cells vs. control cells was $0.97 \pm 0.07,0.90 \pm 0.06$ and $0.49 \pm 0.11 \%$, respectively $(\mathrm{P}<0.05)$. These results suggest that $2 \mathrm{ME}$ sensitizes pituitary adenoma cells to TMZ via the down-modulation of MGMT expression in vivo.

\section{Discussion}

Our study, for the first time, presents experimental evidence that TMZ resistance may be directly correlated with MGMT expression in pituitary adenomas. Furthermore, the HIF-1 $\alpha$ MGMT signaling pathway may be involved in the TMZ resistance of pituitary adenoma cells. HIF-1 $\alpha$ knockdown or inhibitor 2ME may be applied as a mediator of TMZ resistance via the down-modulation of MGMT expression in pituitary adenoma cells. 
Invasive pituitary adenomas are very common in our clinical practice and are characterized by a limited response to standard therapies and poor prognosis (1). When conventional therapies including radiation, surgery, pharmacological treatment fail, TMZ therapy is often adopted as the last line treatment for these life-threatening pituitary adenomas (23). Although a previous report revealed a $60 \%$ response rate for TMZ treatment in invasive pituitary adenomas (20), at least in our center, TMZ exerts poor efficacy in many patients with a much lower response rate. Furthermore, a poor response rate was also observed in many published clinical trials. We believe this discrepancy may be due to the following reasons: Most of the authors tend to report successful cases, and different medical centers may employ different enrollment criteria for TMZ treatment. The schedule and dosing regimens of TMZ treatment varied in different medical centers due to the lack of standard protocol in the treatment of pituitary adenomas (23). Since TMZ is the last line treatment and displays a low response rate in life-threatening pituitary adenoma patients, seeking modulation of TMZ resistance is of high value in our practice.

MGMT expression has been recently reported to be associated with TMZ resistance in patients with gliomas (24). The findings of clinical studies dealing with the association between MGMT expression and the therapeutic response to TMZ in pituitary adenoma patients remain controversial. Some studies report pituitary adenomas with low MGMT expression tend to be responsive to TMZ, while others suggest that no relation exist $(5,19,20,25)$. Moreover, all these previous reports are based on cohorts consisting of a limited number of patients, and, to date, no experimental evidence has been reported. In the present study, MGMT expression was down-modulated by HIF- $1 \alpha$ knockdown or inhibitor $2 \mathrm{ME}$ in vitro and in vivo, suggesting that HIF-1 $\alpha$ inhibition can down-modulate MGMT expression in pituitary adenomas.

There are numerous kinases that can regulate the repair ability of DNA damage in chemotherapy. Checkpoint kinase 1 (Chk1) and MGMT are the key kinases in this process (26). However, in our pre-experiment, inhibition of Chk1 did not lead to a preferential TMZ-induced killing of pituitary adenoma cells. An explanation for this inefficiency may be that most of the human pituitary adenoma cells were wild-type p53 cells (27), which are not hyper-dependent on the $\mathrm{G} 2$ damage-induced checkpoint activity mediated by Chk1 activity. A recent report demonstrated that MGMT expression is dependent on HIF-1 $\alpha$ expression in glioma cells (10), which promoted us to infer that down-modulation of MGMT expression via HIF-1 $\alpha$ inhibition may sensitize pituitary adenoma cells to TMZ treatment. The present study showed that HIF-1 $\alpha$ knockdown or the HIF-1 $\alpha$ inhibitor $2 \mathrm{ME}$ down-modulated MGMT expression, thereby decreasing the double-strand DNA repair capacity as evidenced by the decreased RAD51 protein expression, which in turn sensitized pituitary adenoma cells to TMZ in vitro and in vivo. These results indicate that targeted modulation of MGMT via HIF-1 $\alpha$ inhibition may be a novel way to override TMZ resistance in patients with pituitary adenomas.

There are several inherent limitations to our study. We used cells from primary culture of human pituitary adenomas from two patients in the present study. The cells were not from an established cell line, which may have undermined the signifi- cance of the results of the present study. The reason for this is that there is no well-established human pituitary adenoma cell line (11). Moreover, only a few patients non-responsive to conventional and TMZ therapies in our clinical practice were willing to receive a second operation. Furthermore, due to the benignity of pituitary adenomas, the limited imperfect framework for accessing tumor tissue samples and primary culture technology, many cells from primary cell cultures of human pituitary adenomas almost lose their capability for duplication, and eventually die, which further wastes the valuable but limited human pituitary adenoma tissue. In the present study, HIF-1 $\alpha$ knockdown was only used in vitro, as we employed the HIF-1 $\alpha$ inhibitor $2 \mathrm{ME}$ and obtained the expected results in vivo. $2 \mathrm{ME}$ is an FDA approved anticancer drug which is more likely to be used in our practice than the HIF-1 $\alpha$ knockdown strategy (28). Regarding the mechanism, our results cannot confirm a direct regulatory role of HIF-1 $\alpha$ on MGMT expression as there may be other signaling pathways between the HIF-1 $\alpha$ and MGMT kinases, which require further investigation.

In conclusion, the present study for the first time demonstrates that HIF-1 $\alpha$ modulates MGMT expression in pituitary adenoma cells, and that the HIF-1 $\alpha$ inhibitor $2 \mathrm{ME}$ can sensitize pituitary adenoma cells to TMZ treatment via the down-modulation of MGMT expression. Since both 2ME and TMZ are FDA approved anticancer drugs and can cross the blood-brain barrier $(29,30)$, further research is warranted to define the underlying molecular mechanisms and to optimize the protocol of the combined treatment of TMZ and $2 \mathrm{ME}$ for pituitary adenomas refractory to conventional therapies.

\section{References}

1. Selman WR, Laws ER Jr, Scheithauer BW and Carpenter SM: The occurrence of dural invasion in pituitary adenomas. $J$ Neurosurg 64: 402-407, 1986.

2. Scheithauer BW, Kovacs KT, Laws ER Jr and Randall RV: Pathology of invasive pituitary tumors with special reference to functional classification. J Neurosurg 65: 733-744, 1986.

3. Kreutzer J and Fahlbusch R: Diagnosis and treatment of pituitary tumors. Curr Opin Neurol 17: 693-703, 2004.

4. Ekeblad S, Sundin A, Janson ET, Welin S, Granberg D, Kindmark H, Dunder K, Kozlovacki G, Orlefors H, Sigurd M, Oberg K, Eriksson B and Skogseid B: Temozolomide as monotherapy is effective in treatment of advanced malignant neuroendocrine tumors. Clin Cancer Res 13: 2986-2991, 2007.

5. McCormack AI, McDonald KL, Gill AJ, Clark SJ, Burt MG, Campbell KA, Braund WJ, Little NS, Cook RJ, Grossman AB, Robinson $\mathrm{BG}$ and Clifton-Bligh RJ: Low $\mathrm{O}^{6}$-methylguanineDNA methyltransferase (MGMT) expression and response to temozolomide in aggressive pituitary tumours. Clin Endocrinol 71: 226-233, 2009.

6. Syro LV, Uribe H, Penagos LC, Ortiz LD, Fadul CE, Horvath E and Kovacs K: Antitumour effects of temozolomide in a man with a large, invasive prolactin-producing pituitary neoplasm. Clin Endocrinol 65: 552-553, 2006.

7. Everhard S, Kaloshi G, Criniere E, Benouaich-Amiel A, Lejeune J, Marie Y, Sanson M, Kujas M, Mokhtari K, Hoang-Xuan K, Delattre JY and Thillet J: MGMT methylation: a marker of response to temozolomide in low-grade gliomas. Ann Neurol 60: 740-743, 2006.

8. Stupp R, Hegi ME, Gilbert MR and Chakravarti A: Chemoradiotherapy in malignant glioma: standard of care and future directions. J Clin Oncol 25: 4127-4136, 2007.

9. van Nifterik KA, van den Berg J, van der Meide WF, Ameziane N, Wedekind LE, Steenbergen RD, Leenstra S, Lafleur MV, Slotman BJ, Stalpers LJ and Sminia P: Absence of the MGMT protein as well as methylation of the MGMT promoter predict the sensitivity for temozolomide. Br J Cancer 103: 29-35, 2010. 
10. Persano L, Pistollato F, Rampazzo E, Della PA, Abbadi S, Frasson C, Volpin F, Indraccolo S, Scienza R and Basso G: BMP2 sensitizes glioblastoma stem-like cells to temozolomide by affecting HIF-1alpha stability and MGMT expression. Cell Death Dis 3: e412, 2012.

11. Xiao Z, Liu Q, Zhao B, Wu J and Lei T: Hypoxia induces hemorrhagic transformation in pituitary adenomas via the HIF-1 $\alpha$ signaling pathway. Oncol Rep 26: 1457-1464, 2011.

12. Losa M, Mazza E, Terreni MR, McCormack A, Gill AJ, Motta M, Cangi MG, Talarico A, Mortini P and Reni M: Salvage therapy with temozolomide in patients with aggressive or metastatic pituitary adenomas: experience in six cases. Eur J Endocrinol 163: 843-851, 2010.

13. Wang X, Ma Z, Xiao Z, Liu H, Dou Z, Feng X and Shi H: Chk1 knockdown confers radiosensitization in prostate cancer stem cells. Oncol Rep 28: 2247-2254, 2012.

14. Yang J, Xiao Z, Li T, Gu X and Fan B: Erythropoietin promotes the growth of pituitary adenomas by enhancing angiogenesis. Int J Oncol 40: 1230-1237, 2012.

15. Naumann SC, Roos WP, Jost E, Belohlavek C, Lennerz V, Schmidt CW, Christmann M and Kaina B: Temozolomide- and fotemustine-induced apoptosis in human malignant melanoma cells: response related to MGMT, MMR, DSBs, and p53. Br J Cancer 100: 322-333, 2009.

16. Sadones J, Michotte A, Veld P, Chaskis C, Sciot R, Menten J, Joossens EJ, Strauven T, D'Hondt LA, Sartenaer D, et al: MGMT promoter hypermethylation correlates with a survival benefit from temozolomide in patients with recurrent anaplastic astrocytoma but not glioblastoma. Eur J Cancer 45: 146-153, 2009.

17. van Nifterik KA, van den Berg J, Stalpers LJ, Lafleur MV, Leenstra S, Slotman BJ, Hulsebos TJ and Sminia P: Differential radiosensitizing potential of temozolomide in MGMT promoter methylated glioblastoma multiforme cell lines. Int J Radiat Oncol Biol Phys 69: 1246-1253, 2007.

18. Esteller M, Garcia-Foncillas J, Andion E, Goodman SN, Hidalgo OF, Vanaclocha V, Baylin SB and Herman JG: Inactivation of the DNA-repair gene MGMT and the clinical response of gliomas to alkylating agents. N Engl J Med 343 1350-1354, 2000.

19. Neff LM, Weil M, Cole A, Hedges TR, Shucart W, Lawrence D, Zhu JJ, Tischler AS and Lechan RM: Temozolomide in the treatment of an invasive prolactinoma resistant to dopamine agonists. Pituitary 10: 81-86, 2007.
20. Raverot G, Sturm N, de Fraipont F, Muller M, Salenave S, Caron P, Chabre O, Chanson P, Cortet-Rudelli C, Assaker R, et al: Temozolomide treatment in aggressive pituitary tumors and pituitary carcinomas: a French multicenter experience. J Clin Endocrinol Metab 95: 4592-4599, 2010.

21. Sharma S, Salehi F, Scheithauer BW, Rotondo F, Syro LV and Kovacs K: Role of MGMT in tumor development, progression, diagnosis, treatment and prognosis. Anticancer Res 29: 3759-3768, 2009

22. Baumann P and West SC: Role of the human RAD51 protein in homologous recombination and double-stranded-break repair. Trends Biochem Sci 23: 247-251, 1998.

23. Syro LV, Ortiz LD, Scheithauer BW, Lloyd R, Lau Q, Gonzalez R, Uribe H, Cusimano M, Kovacs K and Horvath E: Treatment of pituitary neoplasms with temozolomide: a review. Cancer 117: 454-462, 2011.

24. Brandes AA, Franceschi E, Tosoni A, Blatt V, Pession A, Tallini G, Bertorelle R, Bartolini S, Calbucci F, Andreoli A, et al: MGMT promoter methylation status can predict the incidence and outcome of pseudoprogression after concomitant radiochemotherapy in newly diagnosed glioblastoma patients. J Clin Oncol 26: 2192-2197, 2008.

25. Takeshita A, Inoshita N, Taguchi M, Okuda C, Fukuhara N, Oyama K, Ohashi K, Sano T, Takeuchi Y and Yamada S: High incidence of low $\mathrm{O}^{6}$-methylguanine DNA methyltransferase expression in invasive macroadenomas of Cushing's disease. Eur J Endocrinol 161: 553-559, 2009.

26. Jackson SP and Bartek J: The DNA-damage response in human biology and disease. Nature 461: 1071-1078, 2009.

27. Levy A, Hall L, Yeudall WA and Lightman SL: p53 gene mutations in pituitary adenomas: rare events. Clin Endocrinol 41: 809-814, 1994.

28. Hagen T, D'Amico G, Quintero M, Palacios-Callender M, Hollis V, Lam F and Moncada S: Inhibition of mitochondrial respiration by the anticancer agent 2 -methoxyestradiol. Biochem Biophys Res Commun 322: 923-929, 2004.

29. Pribluda VS, Gubish ER Jr, Lavallee TM, Treston A, Swartz GM and Green SJ: 2-Methoxyestradiol: an endogenous antiangiogenic and antiproliferative drug candidate. Cancer Metastasis Rev 19: 173-179, 2000

30. Verger E, Gil M, Yaya R, Vinolas N, Villa S, Pujol T, Quinto L and Graus F: Temozolomide and concomitant whole brain radiotherapy in patients with brain metastases: a phase II randomized trial. Int J Radiat Oncol Biol Phys 61: 185-191, 2005. 